\title{
EKRANISASI CERPEN FILOSOFI KOPI KARYA DEWI LESTARI (DEE) \\ KE DALAM FILM FILOSOFI KOPI SUTRADARA ANGGA DWIMAS \\ SASONGKO SEBAGAI ATERNATIF BAHAN AJAR \\ DI SEKOLAH MENENGAH ATAS
}

\author{
Eka Retno Ardianti dan Sri Widayati *)
}

\begin{abstract}
Abtract
The core of the research is ekranisasi of short story Filosofi Kopi becomes the film of Filosofi Kopi. The aim of the research is to describe ekranisasi of short story Filosofi Kopi becomes film of Filosofi Kopi. The result of the research shows that there is enkranisasi shorthenage, addition, and the change of the plot of story, setting, and characters in the form of short story becomes film. Short story and film of Filosofi Kopi can be used as a choice of literature learning, especially learning of ekranisasi because to fulfill criteria of the choice of learning material such as language, psychology, and culture.
\end{abstract}

Key Words: Ekranisasi, short story, Film of Filosofi Kopi

\section{PENDAHULUAN}

Penciptaan sebuah karya sastra ke medium lain seperti film disebut dengan transformasi. Proses transformasi dari cerpen ke dalam film dikenal dengan istilah ekranisasi. Istilah itu berasal dari bahasa Perancis yaitu ecran yang berarti layar. Proses pemindahan dari bentuk cerpen ke dalam film akan mengalami perubahan bentuk dan penyesuaian isi. Ekranisasi merupakan kajian perubahan bentuk dari kata-kata menjadi media audio visual. Eneste (1991:67) membagi perubahan ekranisasi menjadi tiga, yaitu penambahan, penciutan, dan perubahan variasi.

Ekranisasi dapat menghasilkan karya yang bernilai positif, tetapi dapat pula menghasilkan karya yang bernilai negatif, baik bagi publik, pengarang, maupun pembaca. Film hasil ekranisasi dalam pandangan secara umum, yang bernilai positif adalah film yang mampu mempresentasikan cerpen, sedangkan film yang tidak mampu mempresentasikan cerpen dipandang sebagai film hasil ekranisasi yang bernilai negatif (Saputra, 2009:45). Salah satu cerpen yang mengalami proses ekranisasi adalah cerpen karya Dewi Lestari yang memiliki sapaan akrab, yaitu Dee.

Dee mempunyai prestasi yang cukup gemilang. Hal ini dibuktikan dengan terpilihnya cerpen Filosofi Kopi sebagai karya sastra terbaik pada tahun 2006 pilihan majalah Tempo dan menjadi lima besar Katulistiwa Literary Award yang diselenggarakan QB World Book. Cerpen Filosofi Kopi kemudian difilmkan. Fim tersebut mendapat penghargaan di Filipina 
untuk definisi Best Ensamble Performance dan mengikuti beberapa event film internasional.

Cerpen Filosofi Kopi diekranisasi menjadi sebuah film yang disutradarai oleh Angga Dwimas Sasongko dengan judul yang sama dan dirilis pada 9 April 2015. Cerpen Filosofi Kopi karya Dewi Lestari ke dalam film Filosofi Kopi sutradara Angga Dwimas Sasongko. Ekranisasi akan dikaitkan pada pembelajaran sastra dan diharapkan dapat dijadikan sebagai alternatif bahan pembelajaran sastra di sekolah.

Fokus penelitian ini adalah ekranisasi cerpen Filosofi Kopi karya Dewi Lestari (Dee) ke dalam film Filosofi Kopi sutradara Angga Dwimas Sasongko sebagai alternatif bahan ajar di sekolah menemgah atas. Dengan demkian, rumusan masalahnya, yaitu "Bagaimanakah ekranisasi cerpen Filosofi Kopi karya Dewi Lestari ke dalam film Filosofi Kopi sutradara Angga Dwimas Sasongko sebagai alternatif bahan ajar di sekolah menemgah atas?" Adapun tujuan penelitian ini, yaitu mendeskripsikan ekranisasi cerpen Filosofi Kopi karya Dewi Lestari ke dalam film Filosofi Kopi sutradara Angga Dwimas Sasongko sebagai alternatif bahan ajar di sekolah menemgah atas.

\section{KAJIAN TEORI}

Perubahan bentuk dari karya sastra ke dalam bentuk film dikenal dengan istilah ekranisasi. Ekranisasi adalah suatu proses pelayarputihan atau pemindahan sebuah novel ke dalam film. Istilah ini berasal dari bahasa Prancis, ecran berarti layar. Untuk ekranisasi, Damono (2014:13) menggunakan istilah alih wahana untuk pengubahan karya sastra atau kesenian menjadi bentuk kesenian yang lain. Dengan kata lai, karya sastra tidak hanya bisa diterjemahkan, yakni dialihkan dari satu bahasa kebahasa lain, tetapi juga dialihwahanakan, yakni diubah menjadi kesenian lain. Cerita rekaan bisa diubah menjadi tari, drama, atau film. Puisi pun dapat diubah menjadi lukisan. Hayward dalam Damono (2014:143-144) menyatakan bahwa masalah dalam alih wahana dapat disebut sebagai adaptasi. Adaptasi ke film selalu menciptakan kisah yang baru yang tidak sama dengan aslinya. Dalam hal ini adaptasi film bisa menjadi karya yang "lebih" atau "kurang" dibanding aslinya.

Ekranisasi sebenarnya suatu pengubahan wahan dari kata-kata menjadi wahana gambar. Di dalam sebuah karya sastra (novel maupun cerpen) penceritaan dilukiskan dengan kata-kata, sedangkan dalam film penceritaan itu diwujudkan melalui gambar yang dapat dilihat secara langsung. Dengan demikian, ekranisasi adalah pemindahan dan pengubahan dari bentuk kata-kata ke dalam gambar. Waktu yang dibutuhkan untuk membaca karya sastra, seperti novel dan cerpen berbeda 
dengan waktu yang dibutuhkan untuk kualitatif. Penelitian kualitatif lebih menonton sebuah film. mengutamakan proses daripada hasil.

Waktu untuk membaca sebuah karya Pemanfaatan metode ini sesuai dengan sastra lebih luas, sedangkan dalam film tujuan penelitian, yaitu mendeskripsikan waktunya cenderung terbatas. Pemindahan karya sastra ke layar putih mengakibatkan timbulnya berbagai perubahan. Perubahan tersebut meliputi proses penciutan, penambahan, dan perubahan bervariasi (Eneste, 1991:65). Kalau karya sastra berbentuk novel ketika difilmkan sering terjadi penciutan terhadap alur cerita, tokoh, dan latar, tidak demikian halnya dengan karya yang berbentuk cerpen. Dalam cerpen yang terjadi justru sebaliknya. Cerpen yang difilmkan akan terjadi penambahan pada alur cerita, tokoh, dan latar.

Eneste (1991:65) menjelaskan kecuali adanya penciutan dan penambahan, ekranisasi kemungkinan terjadinya variasivariasi tertentu antara novel/cerpen dan film. Karena novel/cerpen mengalami penciutan dan penambahan, memungkinkannya terjadi perubahan bervariasi. Tentu saja secara garis besar cerita tidak mengubah inti dari cerita dalam novel/cerpen. Pemindahan cerita novel/cerpen ke dalam film divariasikan oleh sastrawan dan sutradara untuk membuat daya tarik dan bermanfaat bagi pembaca dan penonton. ekranisasi dalam cerpen Filosofi Kopi karya Dee dan film Filosofi Kopi sutradara Angga Dwimas Sasongko. Sumber data dalam penelitian ini adalah cerpen Filosofi Kopi karya Dee dan film Filosofi Kopi. Instrumen dalam penelitian ini adalah peneliti. Teknik pengumpulan data dalam penelitian ini adalah teknik pencatatan. Teknik analisis data dalam penelitian ini adalah teknik interpretasi. Semi (2012:39) menyatakan bahwa analisis data dapat dilakukan dengan pemberian interpretasi dan melakukan deskripsi bagian demi bagian yang ditemukan dalam penelitian.

\section{HASIL PENELITIAN}

Dari hasil analisis ekranisasi dari cerpen Filosofi Kopi Karya Dee ke dalam Film Filosofi Kopi sutradara Angga Dwimas Sasongko ditemukan proses perubahan variasi, penambahan, dan penciutan pada unsur alur cerita, latar, dan tokoh. Analisis dilakukan dalam empat bagian sesuai dengan isi naskah cerpen.

\section{Ekranisasi Bagian Pertama 1.1 Penambahan Tokoh}

\section{METODE}

Pada bagian pertama, adanya proses

Metode penelitian yang digunakan dalam penelitian ini adalah metode deskriptif ekranisasi penambahan tokoh. Pada cerpen hanya terfokus pada tokoh Ben dan Jody. 
Akan tetapi, di film pada bagian pertama dimunculkan tokoh Nana, Aldi, Arga. Penambahan tokoh tersebut memiliki fungsi untuk memperkuat cerita. Hal ini lakukan supaya secara visual kedai Filosofi Kopi terlihat ramai. Dengan demikian, penambahan tokoh dapat membantu pengembangan cerita dan peran tokoh Ben dan Jody. Selanjutnya, penambahan cerita dan tokoh pada film yang tidak terdapat dalam cerpen, yaitu kehadiran tokoh Cici.Ttokoh tersebut berperan membantu Jody untuk mencari pinjaman uang. Kehadiran tokoh Cici memiliki tujuan menambah konflik dalam cerita.

Hadirnya tokoh pria Batak pada film membawa peran sebagai penagih utang. Selain itu, pria Batak tersebut membawa cerita mengenai utang ayah Jody yang harus dibayar karena sudah jatuh tempo. Jika Jody telat membayar, akan diselesaikan di pengadilan. Selanjutnya sutradara menghadirkan tokoh perempuan bernama El yang tidak terdapat pada cerpen. Penambahan tokoh El dilakukan karena sutradara ingin mengembangkan cerita yang akan dibangun dengan alasan untuk mencukupi waktu tayang pada film. Selanjutnya, dihadirkan tokoh Bang Norman pada film yang tidak terdapat di dalam cerpen. Kehadiran tokoh tersebut untuk memberitahu penonton dari mana Ben dan Jody mendapatkan biji-biji kopi tersebut.

\subsection{Penambahan Latar}

Pada film terdapat penambahan latar tempat yang tidak ditemukan di dalam cerpen, yaitu warung makan. Hadirnya latar tersebut bertujuan untuk memberi penjelasan kepada penonton bahwa di warung makan pun Ben dan Jody dapat berdiskusi. Penambahan tersebut disebabkan karakteristik cerpen yang memiliki keterbatasan dalam menggambarkan latar secara detail dan tidak mendalam.

Berikutnya adalah penambahan latar lapangan golf. Latar tersebut dalam film berfungsi untuk menampilkan suatu peristiwa, yaitu Ben menyetujui tantangan yang diberikan seorang bos. Melalui latar, sutradara ingin menyampaikan kepada penonton bahwa bos itu benar-benar orang kaya. Hal ini terlihat dari olahraga yang dimainkan, bos tersebut, yaitu golf.

Salah satu kegiatan yang dilakukan Ben adalah datang ke tempat acara pelelangan kopi. Hal itu dilakukannya karena ingin mendapatkan biji kopi terbaik. Penambahan latar dalam film karena mengikuti rangkaian cerita yang sudah dibuat. Ben yang ingin mendapatkan biji kopi terbaik maka perlu dihadirkan tempat pelelangan kopi untuk menguatkan cerita.

Penamaan kedai yang digunakan dalam film mengalami penciutan. Pengubahan nama kedai pada cerpen terjadi sebanyak dua kali, tetapi di dalam film tidak ada cerita penggantian nama kedai. Hal itu dilakukan 
karena sutradara ingin memfokuskan nama kedai yang mudah diingat oleh penonton. Penciutan cerita tersebut tidak menimbulkan perbedaan antara cerpen dan film karena tidak mengubah isi cerita dalam cerpen yang tidak dihadirkan di film, yaitu kopi yang dibuat Ben selalu memiliki filosofi.

Di dalam cerpen, Ben membedakan kopi caffe late dan cappuccino dengan memberikan sebuah filosofi dari kopi yang telah dipesan oleh pengunjung kedai. Namun, pada film tidak ada adegan Ben membedakan kedua kopi tersebut. Beberapa alasan tidak dihadirkan cerita tersebut di dalam film dikarenakan, pertama, sutradara sudah memilih terlebih dahulu informasi dalam cerpen yang dianggap penting yang akan ditampilkan pada film. Kedua, adegan atau cerita dalam cerpen tidak begitu penting ditampilkan di layar putih sehingga dihilangkan dalam film.

\subsection{Perubahan Variasi Alur Cerita, Latar, dan Tokoh}

Pada bagian pertama cerpen, pengarang menggambarkan tokoh Ben yang berkeliling dunia untuk belajar meracik kopi yang enak. Hal itu dilakukan Ben karena ingin menjadi barista yang handal. Sementara dalam film, sutradara menampilkan adegan pembuka cerita pembuatan kopi dengan cara modern yang dilakukan oleh tokoh Ben dan cara tradisional yang dilakukan oleh tokoh Pak Seno.

Selain adanya penambahan cerita dan tokoh, terdapat perubahan variasi latar waktu yang berbeda dalam cerpen dan film. Di dalam cerpen, tokoh Jody dan Ben digambarkan pengarang baru bertemu dan tidak saling mengenal sebelumnya. Namun, dalam film, sutradara membuat cerita, Ben dan Jody sudah bersahabat sejak kecil. Perubahan variasi latar waktu terjadi pada film dikarenakan sutradara akan menampilkan kilas balik kehidupan tokoh Ben di masa kecilnya yang berasal dari keluarga petani kopi.

Perubahahan variasi lainnya, yaitu posisi tokoh Jody yang bertugas sebagai kasir digambarkan berada di belakang, sementara dalam film penonton dapat melihat posisi Jody berada di depan sejajar dengan Ben sebagai barista. Perubahan variasi latar dilakukan untuk memfokuskan tugas Jody sebagai kasir yang melayani pembayaran pengunjung saat memesan kopi. Jadi, Jody ditempatkan pada posisi strategis, yaitu di depan.

Selanjutnya ada tokoh di dalam cerpen yang menantang Ben untuk membuat kopi yang enak, yaitu seorang pria perlente berumur 30 tahunan. Namun, dalam film tokoh yang dihadirkan adalah seorang bos (pengusaha properti berumur 50 tahunan). Perubahan variasi tokoh terjadi karena sutradara ingin menampilkan secara visual 
sosok seorang bos. Hal ini dibuktikan dengan hadirnya seorang wanita yang merupakan sekretaris pendamping bos tersebut.

Perubahan variasi tokoh menimbulkan variasi alur cerita yang ada di dalam film. Di dalam cerpen, nominal uang yang ditawarkan adalah 50 juta, sedangkan pada film uang yang ditawarkan adalah 100 juta. Perubahan nominal uang yang dilakukan oleh sutradara agar terlihat logis dengan adanya jalinan cerita yang sudah dibangun mengenai beban utang yang cukup besar senilai 800 juta. Dengan demikian, perubahan nominal dari 50 juta menjadi 100 juta tersebut berpengaruh pada Ben untuk menerima tantangan tersebut.

Dalam cerpen, diceritakan Ben memberi tahu Jody tentang tantangan yang didapatkannya pada saat mereka masih di dalam kedai. Sementara pada film, secara visual dapat dilihat Ben memberi tahu Jody mengenai tantangan tersebut saat mereka di rumah kontrakan. Dengan demkian, terdapat perubahan variasi latar tempat dalam film yang dihadirkan karena sutradara ingin menampilkan latar yang lebih luas dan tidak terfokus hanya di satu tempat saja.

Pada cerpen, setelah Jody mengetahui bahwa Ben mendapatkan sebuah tantangan untuk membuat secangkir kopi houseblend, Jody menyetujui dan mendukung Ben yang berkeinginan untuk merenovasi kedai agar pengunjung semakain ramai yang datang. Hal tersebut karena uang yang ditawarkan dari tantangan tersebut dapat digunakan untuk kemajuan usaha. Namun, terjadi perubahan variasi cerita pada film, yakni uang yang didapatkan dari tantangan tersebut digunakan untuk mencicil hutang. Alasan sutradara melakukan variasi pada film, yaitu untuk menyelaraskan cerita sebelumnya, mengenai hutang ayah Jody yang sudah tidak dicicil selama 4 bulan dan harus dibayar.

\section{Ekranisasi Pada Bagian Kedua}

Pada bagian kedua, tokoh Ben digambarkan dalam cerpen sedang menelepon penantangnya untuk datang ke kedai mencicipi kopi perfecto. Namun, pada film, cerita itu diciutkan atau tidak dihadirkan. Hal itu dikarenakan cerita pada film menggambarkan bahwa Ben belum mendapatkan tantangan untuk membuat kopi. Cerita pada film dihilangkan karena sutradara telah memilih bagian atau informasi yang dianggap penting untuk ditampilkan. Hal itu menunjukkan bahwa sutradara ingin mengembangkan cerita agar tampak berbeda

\section{Ekranisasi Pada Bagian Ketiga Proses Ekranisasi Alur Cerita, Latar, dan Tokoh}

Cerita di dalam film berlanjut ketika Ben mendengar pernyataan El yang mengatakan bahwa kopi yang dibuat Ben memiliki rasa yang biasa saja. Seketika Jody langsung mencari informasi tentang El 
melalui internet. Informasi yang didapat bahwa El merupakan seorang yang ahli dalam menilai rasa kopi. Dari keterangan tersebut terlihat penambahan cerita pada film.

Sutradara melakukan penambahan cerita bertujuan untuk memunculkan konflik pada film yang akan membuat cerita lebih menarik. Selain itu konflik mengenai Ben yang tidak terima kopi perfecto buatannya disamakan dengan kopi yang dibuat petani kampung adalah jalinan cerita yang telah dihadirkan

Ben yang tidak mau mencari kopi tiwus, membuat Jody mengambil keputusan yang tidak disangka Ben, yaitu Jody berniat menjual kedai. Sutradara menambahkan cerita pada film yang tidak ditemukan pada cerpen. Cerita itu dihadirkan oleh sutradara karena untuk menguatkan jalinan cerita sebelumnya, mengenai hutang yang sudah jatuh tempo. Keadaan saldo kedai yang tidak mencukupi, membuat Jody berpikir menjual kedai dengan harapan uang penjualan dapat digunakan untuk mencicil hutang.

Penambahan cerita dalam film yang tidak ditemukan dalam cerpen ketika Ben yang akhirnya ingin mencari kopi tiwus. Hal tersebut dikarenakan saat Ben yang tidak sengaja melihat Nana menumpahkan biji-biji kopi dan membuat Ben teringat pada masa lalu. Ia memiliki trauma di waktu kecil dengan keluarganya. Mengetahui Nana sedang mengalami kesulitan keuangan dengan musibah yang dialaminya dan saldo dalam kedai yang tidak mencukupi untuk membantu Nana, Ben akhirnya mau untuk mencari kopi tiwus.

Jalinan cerita pada film yang menggambarkan tokoh Ben tidak ingin minum kopi tiwus sebelum melihat proses pembuatannya, membuat sutradara menambahkan latar kebun kopi yang di dalam cerpen tidak dihadirkan oleh pengarang. Fungsi penambahan latar tersebut untuk menguatkan tokoh Ben yang tidak yakin dengan kopi tiwus. Ketidakyakinan Ben karena ia tidak percaya kopi yang ditanam di daerah perbukitan dapat mengalahkan kopi Perfecto yang dibuat secara modern.

Pada saat Ben sudah tiba di kebun kopi, terdapat penambahan cerita mengenai Ben yang teringat pada masa kecilnya. Pada waktu itu, Ben diajak oleh ayahnya pergi ke kebun kopi untuk mengetahui cara merawat kopi yang benar. Alasan sutradara menghadirkan cerita tentang masa kecil Ben untuk meng-informasikan kepada penonton bahwa ia pandai dalam meracik kopi karena ayahnya adalah seorang petani kopi.

Setelah pulang dari warung Pak Seno, dalam cerpen pengarang menggambarkan tokoh Ben dan Jody kembali ke kedai. Sementara dalam film, sutradara menampilkan tokoh Jody, Ben dan El tidak ke kedai, melainkan ke rumah kontrakan. Penambahan latar tersebut memberikan 
informasi kepada penonton bahwa latar yang ditampilkan dalam film tidak terfokus pada satu latar saja.

Saat waktu yang telah ditentukan, Ben dan Jody datang ke perusahaan milik bos (penantang Ben untuk membuat houseblend) tempat Ben menyuguhkan kopi yang diminta penantangnya. Pada cerita film, ada tambahan tokoh yang tidak ditemukan dalam cerpen. Tokoh tersebut adalah seorang pria investor. Sutradara menghadirkan tokoh pria investor itu untuk mencicipi kopi houseblend buatan Ben. Dengan hadirnya pria investor itu akan menentukan Ben dapat memenangkan uang 1 milyar.

Akhirnya Ben berhasil memenangkan cek 1 milyar dan Jody merasa senang sekali. Namun, tidak diduga Jody, Ben kemudian memutuskan untuk berhenti menjadi barista (orang yang pekerjaannya membuat dan menyajikan kopi kepada pelanggan). Ben pamit kepada Jody, Nana, Aldi, dan Arga.

Setelah memutuskan untuk meninggalkan kedai, Ben datang ke pemakaman bapak Jody. Penambahan latar tersebut memiliki fungsi untuk memberi tahu kepada penonton bahwa Ben ingin menyampaikan secara tidak langsung bahwa hutang yang ditinggali ayah Jody sudah lunas. Selain itu, penggambaran tokoh Ben yang membersihkan makam yang ditumbuhi rumput menunjukkan rasa sayangnya kepada ayah Jody.

\subsection{Proses Penciutan Latar Cerita}

Pada cerpen diceritakan Ben dan Jody menginap di Klaten karena mereka tidak dapat menemukan lokasi kopi tiwus. Namun, pada film, latar Klaten tidak dihadirkan. Sutradara tidak menampilkan latar tersebut karena latar Klaten tidak terlalu penting untuk dihadirkan. Jika latar tersebut ditampilkan, hal tersebut akan menambah waktu putar, padahal film dibatasi oleh durasi waktu. Dengan demikian, sutradara memilih untuk tidak menampilkan cerita tersebut.

\subsection{Proses Perubahan Variasi Tokoh}

Dalam bagian ketiga, ditemukan ekranisasi bagian perubahan variasi tokoh di film. Pada cerpen digambarkan tokoh Ben tampak hafal setiap orang yang datang ke kedainya. Ben melihat ada pengunjung baru datang ke kedainya, yaitu seorang pria paruh baya. Namun, visualisasi dalam film tokoh pria paruh baya mengalami perubahan variasi dari segi nama tokoh dan jenis kelamin. Tokoh tersebut bernama El (seorang perempuan yang cantik). El digambarkan sedang melakukan penelitian tentang biji kopi yang telah diolah menjadi minuman.

Alasan terjadinya perubahan variasi tokoh yang dilakukan oleh sutradara, yaitu sutradara ingin menampilkan sosok El yang mengetahui tentang kopi. Hal ini dapat 
dilihat ketika El mewawancarai Jody yang sudah dihadirkan sebelumnya mengenai kopi perfecto buatan Ben.

Dalam cerpen, tokoh pria paruh baya mengenai Ben yamg sebenarnya tidak tertarik mencari kopi tiwus.

menganggap kopi perfecto buatan Ben

Dalam cerpen setelah Ben meminum memiliki rasa yang biasa saja. Hal itu dikarenakan ia pernah minum kopi yang rasanya jauh lebih enak dari kopi perfecto. Kopi itu bernama kopi tiwus. Mendengar hal itu, Ben ingin mencari dan merasakan rasa kopi tiwus. Namun pada film, terjadi perubahan variasi peran tokoh. Dalam cerpen tokoh yang berperan mencicipi kopi tiwus adalah Ben, sedangkan di film Jody. Dari hal tersebut, sutradara ingin menyampaikan kepada penonton, bahwa perubahan peran tokoh Jody yang ingin mencicipi kopi tiwus untuk menguatkan karakter Jody yang terpengaruh oleh ucapan El tentang kopi tiwus. Pada film juga terdapat penambahan tokoh El sebagai penunjuk jalan dalam mencari kopi tiwus.

Dalam film pun terjadi perubahan cerita tentang makanan yang disajikan oleh Pak Seno. Pada cerpen yang disuguhkan adalah gorengan, sedangkan pada film disajikan kacang yang diolah dengan cara sangrai. Selanjutnya perubahan juga tampak dalam film. Jika pengarang dalam cerpen menggambarkan tokoh Ben langsung meminum kopi tiwus buatan Pak Seno, tidak demikian halnya dalam film, Ben tidak meminum kopi sebelum melihat proses pembuatannya. Hal itu divariasikan oleh sutradara karena untuk melanjutkan cerita kopi tiwus, ia memberikan uang hasil tantangan yang dimenangkannya dari pria perlente untuk diberikan kepada Pak Seno. Namun, Jody tidak menyetujuinya karena uang yang didapatkan dari pria perlente tersebut untuk pengembangan usaha kedai. Sementara pada film, setelah selesai melihat kebun Pak Seno, Ben kembali ke warung dan akhirnya meminum kopi tiwus. Terjadi perubahan variasi cerita mengenai uang yang diserahkan kepada Pak Seno. Pada film, sutradara menggambarkan tokoh Ben belum memenangkan tantangan yang telah diberikan oleh bos (pengusaha properti) itu karena jalinan cerita yang dibuat berbeda dari jalinan cerpen. Jadi, uang yang diberikan kepada Pak Seno adalah uang pribadi Ben.

\section{Ekranisasi Pada Bagian Keempat}

\subsection{Proses Ekranisasi Penambahan Alur} Cerita, Latar, dan Tokoh

Pada bagian empat atau bagian penutup pada cerpen dan film terdapat beberapa ekranisasi, yaitu penambahan, perubahan variasi, dan penciutan. Di dalam film, terdapat penambahan cerita yang tidak ditemukan dalam cerpen, yaitu Ben pulang ke rumah ayahnya di Liwa, Lampung. Setelah sampai, Ben memeluk ayahnya dan kemudian menerima surat dari ayahnya yang 
sudah lama disimpan. Surat tersebut dihadirkan berbeda dengan cerpen. merupakan peninggalan ibu Ben. Sutradara menampilkan surat yang berisi kejadian penyebab ibu Ben meninggal. Penambahan cerita yang ada pada film merupakan rangkaian alur yang telah disusun.

Selanjutnya, pada cerpen digambarkan tokoh Jody yang sangat sibuk mengurus kedai seorang diri. Namun, pada film, Jody dibantu Maliq yang bertugas sebagai barista. Penambahan tokoh yang dihadirkan oleh sutradara karena Jody yang bertugas sebagai kasir tidak mungkin dapat meracik kopi dan membuat kopi untuk pengunjung yang datang ke kedai. Dengan demikian, dihadirkan tokoh Maliq dalam film untuk bertugas sebagai barista di kedai.

Adegan selanjutnya terdapat penambahan cerita pada film, yaitu terbitnya buku tentang kopi yang ditulis oleh El. Penambahan cerita tersebut memiliki fungsi untuk memberi tahu kepada penonton bahwa keinginan El dalam menulis buku tentang kopi dengan segala riset yang telah dilakukan telah terwujud.

\subsection{Proses Ekranisasi Penciutan Alur Cerita}

Pada cerpen, pengarang menggambarkan tokoh Pak Seno menerima kiriman cek dari Jody, tetapi cek itu hanya disimpan di dalam lemari. Namun, pada film, cerita itu diciutkan atau tidak dihadirkan. Hal itu dilakukan karena jalinan cerita yang

\subsection{Proses Ekranisasi Perubahan Variasi Alur Cerita, Latar, dan Tokoh \\ Dalam cerpen Jody sedang membuat} kopi dan terkenang dengan masa-masa yang telah dilalui bersama Ben. Sementara pada film, Jody sedang menyaksikan video sewaktu ia kecil bersama Ben. Tokoh Jody pada cerpen yang tidak memiliki keterampilan dalam membuat kopi tidak ditampilkan. Terjadi perubahan variasi cerita yang dilakukan sutradara karena ingin memfokuskan tugas Jody hanya sebagai kasir saja. Dengan demikian, dalam film cerita diubah menjadi menonton video yang memperlihatkan kedekatan Jody dan Ben yang sudah terjalin sejak kecil.

Pada cerpen diceritakan tokoh Jody meninggalkan kedai. Namun, dalam film Ben pergi dari kedainya yang ada di Jakarta dan pulang ke rumah ayahnya yang berada di Liwa, Lampung untuk mencari ketenangan. Peristiwa tersebut memperlihatkan terjadi perubahan peran tokoh. Sutradara ingin menggambarkan tokoh Ben yang merasa malu karena kopi tiwus buatan Pak Seno ternyata lebih enak dibandingkan kopi perfecto buatan Ben. 
Dengan nasihat ayahnya, Ben kembali ke Jakarta. Saat Ben tiba di Jakarta, ia terkejut melihat tulisan yang ada di kaca kedai yang bertuliskan Kedai Telah Terjual. Dari uraian tersebut tampak perubahan variasi cerita film. Pengarang menggambarkan kedai dalam cerpen tidak dijual, tetapi di dalam film ditampilkan adegan bahwa kedai dijual. Alasan sutradara melakukan variasi cerita itu dikarenakan, pertama, ingin mengaitkan jalan cerita yang sebelumnya sudah ditampilkan, yaitu kehadiran seorang fotografer yang diundang Jody untuk datang ke kedai melihat-lihat bagian dalam kedai. Secara visualisasi, penonton dapat mengetahui kedatangan fotografer tersebut untuk mempromosikan kedai yang diiklankan karena akan dijual.

Adegan penutup pada cerpen dan film mengalami perubahan variasi. Perubahan variasi tersebut, yaitu latar tempat yang dihadirkan. Pada cerpen, pengarang menggambarkan latar kedai masih berada di sebuah ruko dan tidak pindah. Namun, pada film, kedai Filosofi Kopi berada di bus. Adanya perubahan latar karena jalinan cerita yang sudah dihadirkan sebelumnya bahwa kedai sudah terjual. Dengan demikian, penonton dapat melihat kedai yang sudah terjual tidak lagi berada di dalam sebuah ruko, melainkan berada di bus. Pengunjung yang datang dapat duduk di kursi yang telah disiapkan di sekitar bus.
Dilihat dari aspek kebahasaan, cerpen dan film Filosofi Kopi dapat dijadikan sebagai alternatif bahan pembelajaran karena menggunakan bahasa sehari-hari yang mudah dipahami siswa. Pada aspek psikologi, cerpen dan film Filosofi Kopi dapat memberi pemahaman kepada siswa SMA dalam menyelesaikan masalah yang sedang dihadapi dan dapat mengendalikan diri sesuai dengan aturan-aturan dalam masyarakat. Aspek latar belakang budaya pada cerpen dan film Filosofi Kopi sesuai dengan kondisi lingkungan siswa sehari-hari. Dengan demikian, cerpen dan film Filosofi Kopi memenuhi kriteria dalam pemilihan bahan ajar dan dapat dijadikan alternatif bahan ajar.

\section{SIMPULAN}

Berdasarkan temuan penelitian, dapat disimpulkan bahwa cerpen Filosofi Kopi karya Dewi Lestari merupakan cerpen yang mengalami ekranisasi ke dalam film Filosofi Kopi sutradara Angga Dwimas Sasongko. Ekranisasi yang terjadi pada cerpen ke dalam film meliputi alur, tokoh, dan latar berupa penciutan, penambahan, dan perubahan variasi.

Berdasarkan hasil temuan tentang ekranisasi tersebut, cerpen dan film Filosofi Kopi dapat dijadikan sebagai alternatif bahan pembelajaran sastra, khususnya pembelajaran ekranisasi karena memenuhi 
kriteria pemilihan bahan ajar, yaitu bahasa, psikologi, dan latar belakang budaya. Selain itu, cerpen dan film Filosofi Kopi dapat dijadikan sebagai alternatif bahan ajar karena bermanfaat untuk membantu siswa memahami pemindahan cerita dari cerpen ke dalam film.

\section{DAFTAR RUJUKAN}

Ardianto. 2007. Pembelajaran Sastra sebagai Sarana Pengembangan Daya Nalar Siswa. Dalam Jurnal Igra. (Daring). Vol. 3 (1) 57-67. Tersedia http://jurnaligra. File. Wordpress.com (28 November 2015).

Damono, Sapardi Djoko. 2014. Alih Wahana. Jakarta: Editum.

Dermawan. 2016. Biodata dan Profil Lengkap Dwimas Sasongko dengan Foto Terbaru. (Daring). Tersedia: www.lihat.co.id/biodata/dwimassasongko.html. (25 Agustus 2016).

Eneste, Pamusuk. 1991. Novel dan Film. Flores: Nusa Indah.

Ezra, Reino. 2015. Film Filosofi Kopi Terus Keliling Festival Dunia. (Daring). Tersedia:

http://m.muvila.com/film/artikel/fi lm-filosofi-kopi-keliling-festivaldunia 151110n. html. (20 Maret 2016).

Hutcheon, Linda. 2006. A Theory of Adaptation. New York: Routledge.
Lestari, Dewi. 2015. Filosofi Kopi. Yogyakarta: Bentang.

Maghfiroh, Lailatul, Mariati Sri, dan Maslikatin Titik. 2013. Ekranisasi Cerpen Jendela Rara Ke Film Rumah Tanpa Jendela: Kajian Psikologi Anak. Dalam Jurnal Publika Budaya, Vol.1 (1):1—15.

Nurgiyantoro, Burhan. 2014. Penilaian Pembelajaran Bahasa Berbasis Kompetensi. Yogyakarta: BPFE.

Nurgiyantoro, Burhan. 2013. Teori Pengkajian Fiksi. Yogyakarta: Gadjah Mada University Press.

Rahmanto, B. 2005. Metode Pengajaran Sastra. Yogyakarta: Kanisius.

Rokhani, Umilia. 2008. Bahasa dan Sastra dalam berbagai Perspektif: Tinjauan Teori Pembacaan dalam Film Adaptasi Novel. Yogyakarta: Tiara Wacana.

Saputra, Heru S.P. 2009. Transformasi Lintas Genre: dari Novel ke Film, dari Film ke Novel. Dalam Jurnal Humaniora, Vol.21 (1):41-55.

Sasongko, Angga Dwimas. 2015. Film Filosofi Kopi. Jakarta: Visinema Pictures. Semi, Atar. 2012. Metode Penelitian Sastra. Bandung: Angkasa.

Siswanto, Wahyudi. 2008. Pengantar Teori Sastra. Jakarta: Gramedia.

Susanto, Dwi. 2012. Pengantar Teori Sastra. Yogyakarta: CAPS.

Teeuw. A. 2013. Sastra dan Ilmu Sastra. Bandung: Pustaka Jaya. 
Ekranisasi Cerpen Filosofi Kopi Karya Dewi Lestari (Dee) ke Dalam Film Filosofi Kopi Sutradara Angga Dwimas Sasongko Sebagai Aternatif Bahan Ajar di Sekolah Menengah Atas (Eka Retno Ardianti dan Sri Widayati) 